\title{
A Planar Ultrawideband Patch Antenna Array for Microwave Breast Tumor Detection
}

\author{
Amran Hossain ${ }^{1}\left(\mathbb{D}\right.$, Mohammad Tariqul Islam ${ }^{1, *} \mathbb{( D}$, Md. Tarikul Islam ${ }^{1}(\mathbb{D}$, \\ Muhammad E. H. Chowdhury ${ }^{2, *(D)}$, Hatem Rmili ${ }^{3, *}$ a and Md. Samsuzzaman 4 (D) \\ 1 Department of Electrical Electronic and Systems Engineering, Universiti Kebangsaan Malaysia, \\ Bangi 43600, Selangor, Malaysia; p102123@siswa.ukm.edu.my (A.H.); p94299@siswa.ukm.edu.my (M.T.I.) \\ 2 Department of Electrical Engineering, Qatar University, Doha 2713, Qatar \\ 3 Center of Research Excellence in Renewable Energy and Electrical Power Systems (CREPS), \\ King Abdulaziz University, P.O. Box 80204, Jeddah 21589, Saudi Arabia \\ 4 Patuakhali Science and Technology University, Patuakhali 8602, Bangladesh; samsuzzaman@ukm.edu.my \\ * Correspondence: tariqul@ukm.edu.my (M.T.I.); mchowdhury@qu.edu.qa (M.E.H.C.); \\ hmrmili@kau.edu.sa (H.R.); Tel.: +60-193666192 (M.T.I.); +97431010775 (M.E.H.C.)
}

Received: 14 June 2020; Accepted: 16 July 2020; Published: 2 November 2020

\begin{abstract}
In this paper, a compact planar ultrawideband (UWB) antenna and an antenna array setup for microwave breast imaging are presented. The proposed antenna is constructed with a slotted semicircular-shaped patch and partial trapezoidal ground. It is compact in dimension: $0.30 \lambda \times 0.31 \lambda \times 0.011 \lambda$, where $\lambda$ is the wavelength of the lowest operating frequency. For design purposes, several parameters are assumed and optimized to achieve better performance. The prototype is applied in the breast imaging scheme over the UWB frequency range 3.10-10.60 GHz. However, the antenna achieves an operating bandwidth of $8.70 \mathrm{GHz}(2.30-11.00 \mathrm{GHz})$ for the reflection coefficient under- $10 \mathrm{~dB}$ with decent impedance matching, $5.80 \mathrm{dBi}$ of maximum gain with steady radiation pattern. The antenna provides a fidelity factor (FF) of $82 \%$ and $81 \%$ for face-to-face and side-by-side setups, respectively, which specifies the directionality and minor variation of the received pulses. The antenna is fabricated and measured to evaluate the antenna characteristics. A 16-antenna array-based configuration is considered to measure the backscattering signal of the breast phantom where one antenna acts as transmitter, and 15 of them receive the scattered signals. The data is taken in both the configuration of the phantom with and without the tumor inside. Later, the Iteratively Corrected Delay and Sum (IC-DAS) image reconstructed algorithm was used to identify the tumor in the breast phantom. Finally, the reconstructed images from the analysis and processing of the backscattering signal by the algorithm are illustrated to verify the imaging performance.
\end{abstract}

Keywords: ultrawideband; semicircular-shaped; breast tumor; patch antenna; microwave imaging

\section{Introduction}

Globally, breast cancer is stated to be a foremost reason for women's death. Each year, approximately $25 \%$ of new cases of breast cancer are identified [1]. Breast cancer begins by owing to the existence of malignant cells in the breast tissues. Currently, this disease is considered a major women's health problem worldwide [2], and a reliable early stage diagnosis is seen as the key aspect in treating it. If it is possible to detect breast cancer in early stages by using a reliable technique, then the treatment may attain a survival percentage of up to $97 \%$ [3]. The standard technologies in medical imaging such as Computed Tomography (CT), Magnetic Resonance Imaging (MRI), Ultrasound, and X-ray mammography are usually used for detecting cancerous breast cells or tumors [4,5]. The main advantages of CT scanning are (1) particularly suitable for identifying acute and chronic changes to 
the internal structure of the human body, (2) rapid acquisition of images, (3) excellence in diagnosing diseases of the large vessels [6]. However, the main disadvantages of CT scanning are (1) exposure to radiation, and (2) performance deprivation [6,7]. The prime benefits of MRI are (1) excellent in diagnosis of disease of the large vessels, (2) more accurate information about scanning object, and (3) MRI helps doctors to evaluate different parts of the human body, as well as to detect the presence of a particular disease (e.g., breast tumor) [8]. However, the disadvantages of this technology are that (1) it takes a long time for testing, (2) the cost is higher, and (3) the compression of body parts is uncomfortable, and ionizing radiation poses a high risk [8,9]. The ultrasound technique is better for a particular domain, and it has no ionizing radiation, but the main disadvantages are that (1) it produces low-resolution images, (2) image perfection depends on the technicians, and (3) it is hard to identify the deep-lying tumor [10]. The X-ray mammography technique has some advantages such as (1) it is a simple technique and cheaper in terms of cost, (2) it produces lower radiation compared to a CT scan, and (3) it helps to detect alien objects inside the bone. However, the main limitations are (1) it increases high false-negative rates, (2) low-quality image with low sensitivity, as well as (3) due to short ionizing radiation, it increases the cancer risk [11]. Finally, a well-known limitation of the X-ray is its associated pain. It requires compression of the breast, and many women choose to not go in for screening for this reason. Thus, at present, microwave imaging (MWI) is a promising technique for breast tumor detection due to non-ionizing radiation upshot, efficient, low profile, low cost, and comfort in respect to traditional medical identification technologies such as CT scan, MRI or X-ray. Due to the features of MWI, the researchers are motivated to establish an MWI framework to identify the breast tumor. The fundamental use of MWI is to distinguish the dielectric properties of tumorous and normal cells in the breast tissues. With respect to breast tumors, there is a momentous difference between the dielectric properties of normal breast tissue and a malignant cell (i.e., tumor cell). The malignant breast tumor dielectric properties are higher than that of the normal breast tissue, which is a significant aspect for using the microwave as breast imaging for the detection of malignant cells [12].

However, microwave antennas played a prime role in this technology and are able to easily distinguish the small pulse alterations from the variations of the electrical properties of human tissues. In this imaging technique, the antenna transmits microwave pulses across the target object. On the other hand, the receiver receives the scattered pulses in several directions. Owing to having dissimilar dielectric characteristics of the different tissue, the received scattered pulse delivers significant data about pulse propagation across the cells. Then, applying different algorithms on received scattered signals, it is possible for the image of the specific object, such as a breast tumor, to be plotted. However, the main objective of MWI is to design a trustworthy, low-cost, low-profile imaging system that can be used for medical diagnosis purposes. At present, in MWI technology, the ultrawideband (UWB) antenna is used to detect a tumor in the breast because of its extraordinary features such as high data rate, high resolution, low complexity, low profile, lightweight, good efficiency, and radiation directivity [13]. The wideband feature provides high-quality resolution images and precise localization of a target object for imaging [14]. For attaining improved outcomes in the breast imaging platform, UWB antennas are a suitable candidate $[15,16]$. Therefore, the design of the appropriate UWB antenna is a requirement in the breast MWI system. However, a number of ultrawideband antennas have been designed for ultrawideband applications, such as the planar inverted cone antenna [17], combinations of the monopole and slot antenna [18], and the volcano smoke antenna [19] for ultrawideband applications. In addition, several UWB antennas are proposed for MWI; for instance, parasitic resonator-based UWB antennas [20-22], slotted UWB antennas [23], tunable UWB antennas [24], sensor-based UWB antennas [13], different types of Vivaldi antennas [4,25-31], directional UWB antennas [32-35], CPW UWB antennas [36], EBG-based UWB antennas [37,38], polarized-UWB antenna arrays [39,40], and different types of patch antennas [13,41]. However, a parasitic resonator-based UWB antenna was proposed for breast imaging in [21]. In this approach, antenna size is $30 \times 29 \times 1.6 \mathrm{~mm}^{3}$, but its gain is comparatively low, with low imaging resolution. Different kinds of Vivaldi antennas were designed in [4,25-31] with comparatively high resolution, but the size is large concerning the 
proposed antenna. A CPW-fed UWB antenna was proposed in [30] for breast imaging, with two rotating antenna array platforms, but the gain is poor, the scanning image resolution is not high, and the antenna size is very large. In [37,38], EBG-based UWB antennas were proposed for ultrawideband applications. Due to the inefficient design of the antenna, the gain was relatively poor, and scanning image resolution was not satisfactory.

In this paper, a compact planar UWB antenna for breast imaging is presented. Significantly, a UWB antenna should have the ability to produce more than one resonance in MWI applications [20]. This feature is vital for producing a high-quality image and good penetration in the depth portion of the object [27]. Besides, the antenna should also have a higher gain, wider bandwidth, high efficiency, and directional radiation pattern than microstrip patch antennas. Hence, in this article, a new planar ultrawideband antenna has been introduced and clarified its overall characteristics. The dimension of the antenna is $0.30 \lambda \times 0.31 \lambda \times 0.011 \lambda$, where $\lambda$ is the wavelength of the lowest operating frequency. It attains an operational bandwidth of $2.30 \mathrm{GHz}$ to $11.00 \mathrm{GHz}$, with a maximum gain of $5.80 \mathrm{dBi}$ and directional radiation. The antenna produces multiple resonance frequencies, directional radiation, and higher fidelity factor $(>80 \%)$, which are prerequisites for microwave breast imaging. The time-domain and frequency-domain features of the antenna have been investigated to evaluate antenna performance. Sixteen antenna arrays are used and placed vertically and horizontally, surrounding the imaging arrangement for the breast phantom imaging to detect the tumor inside the breast. Finally, the simulation environment and the imaging outcomes are demonstrated in the results section.

\section{Design Methodology of the Proposed Antenna}

Significantly, a UWB antenna should have the ability to produce more than one resonance in MWI applications [20]. This feature is vital for producing high-quality images and good penetration in the depth portion of the object [27]. The antenna should also have higher gain, wider bandwidth, high efficiency, and a directional radiation pattern. Hence, in this article, a new planar ultrawideband antenna has been introduced and its overall characteristics are clarified. The geometry and fabricated prototype of the antenna are depicted in Figures 1 and 2, respectively. The antenna is designed on the Rogers RT5880 dielectric substrate material. The thickness $\left(T_{h}\right)$, relative permittivity $\left(\varepsilon_{r}\right)$, and loss tangent $(\delta)$ of the substrate is $1.575 \mathrm{~mm}, 2.2$ and 0.0009 , respectively. The magenta and green colors in the graphical design are considered copper with 0.035 thickness. The proposed antenna has a slotted semicircle-shaped radiating patch along with a trapezoidal-shaped ground plane, which is coupled to a $50 \Omega$ tapered-shaped microstrip-fed line. The tapered-shaped feed line is designed for impedance matching, and a small semicircle-shaped slot is cut out from the radiating patch to enhance the radiation directivity. A partial trapezoidal ground plane is attached to the ground for increasing the entire bandwidth. All design parameters of the prototype are shown in Table 1. 


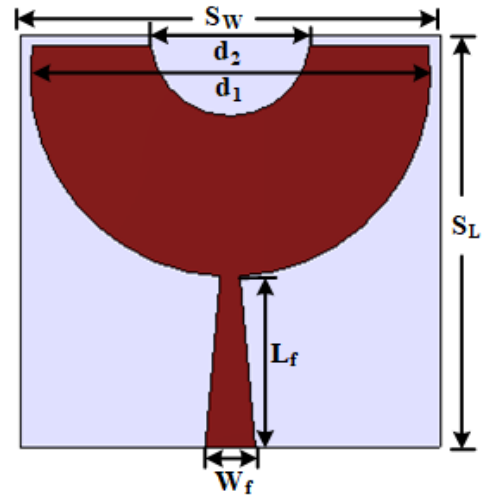

(a)

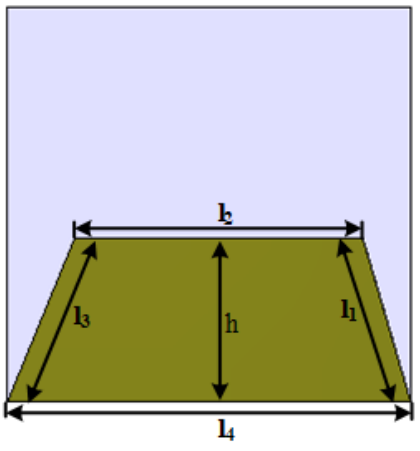

(b)

Figure 1. Geometric structure of the proposed antenna: (a) Front view; (b) Rear view.

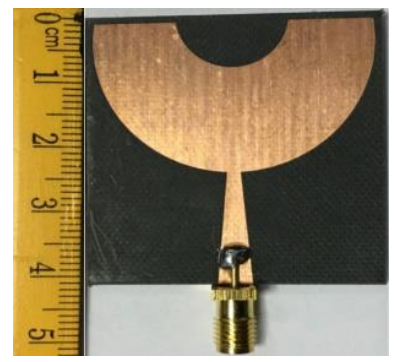

(a)

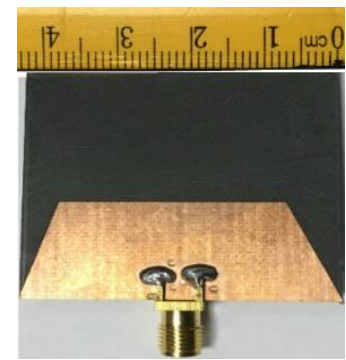

(b)

Figure 2. Fabricated prototype: (a) Front view; (b) Rear view.

Table 1. All optimized parameters of the proposed prototype.

\begin{tabular}{cccc}
\hline Parameters & Size $(\mathbf{m m})$ & Parameters & Size $(\mathbf{m m})$ \\
\hline$S_{w}$ & 42 & $l_{1}$ & 17.72 \\
$S_{L}$ & 41 & $l_{2}$ & 30 \\
$d_{1}$ & 40 & $l_{3}$ & 18.38 \\
$d_{2}$ & 15 & $l_{4}$ & 42 \\
$L_{f}$ & 17 & $h$ & 17 \\
$W_{f}$ & 5 & & \\
\hline
\end{tabular}

\section{Parametric Study of the Proposed Antenna}

There are 11 parameters in the antenna design; those are used, and their values are optimized for attaining the overall operating frequency band. In this work, the preliminary design has been investigated in both HFSS and CST simulators to assess performance of the antenna. The two simulators work on two different methods. Therefore, before fabricating the prototype, we checked the results from both simulators for accuracy of the designed antenna. This matching between both the simulators guarantees that the fabricated prototype will show expected performance while measuring. The various modified structures of the antenna are depicted in Figure 3. The length and width of the antenna are represented by $S_{L}$ and $S_{w}$, respectively. The value of the $S_{L}$ and $S_{w}$ is considered $41 \mathrm{~mm}$ and $42 \mathrm{~mm}$, which is the optimized size for achieving the operating band from $2.26 \mathrm{GHz}$ to $11.00 \mathrm{GHz}$. A partial trapezoidal ground is attached to the backplane of the substrate material. The length of the trapezoidal arms of the ground plane is represented by $l_{1}, l_{2}, l_{3}$, and $l_{4}$, and the height of the ground denoted by $h$. The considered values are $17.72 \mathrm{~mm}, 30 \mathrm{~mm}, 18.38 \mathrm{~mm}$, and $42 \mathrm{~mm}$, and height is $17 \mathrm{~mm}$, respectively, which is the optimized size for achieving the operating band from $2.26 \mathrm{GHz}-11.00 \mathrm{GHz}$. The dimension of the main semicircle-shaped radiator is represented by $d_{1}$. A $15 \mathrm{~mm}$ semicircle-shaped slot has been 
cut off from the central location of the patch to increase the radiation directivity. Figure 4a depicts the reflection coefficient of different modification structures of the prototype. First investigated is that, in normal patch design, the antenna produces four resonances in the frequency ranges from $2.26 \mathrm{GHz}$ to $10.00 \mathrm{GHz}$, but the reflection coefficient curve goes to upward from $-10 \mathrm{~dB}$ in between the frequency ranges from $3.00 \mathrm{GHz}$ to $4.00 \mathrm{GHz}$. So, the operating frequency range is from $2.26 \mathrm{GHz}$ to $3.00 \mathrm{GHz}$, which does not cover ultrawideband. Second, in the slotted patch design, the antenna produces three resonances at $3.00 \mathrm{GHz}, 4.50 \mathrm{GHz}$, and $6.50 \mathrm{GHz}$ under $-15 \mathrm{~dB}$ in the frequency ranges of $2.30 \mathrm{GHz}$ to 7.00 GHz. The highest resonance pick has produced under $-30 \mathrm{~dB}$ at $4.50 \mathrm{GHz}$. However, the operating frequency range is from $2.30 \mathrm{GHz}$ to $7.00 \mathrm{GHz}$, and it does not cover an ultrawideband frequency range. Finally, in the proposed design, the antenna produces three resonances at $3.50 \mathrm{GHz}, 5.50 \mathrm{GHz}$, and $10.00 \mathrm{GHz}$ under $-18 \mathrm{~dB}$ in the frequency range from 2.26 to $11.00 \mathrm{GHz}$. The highest resonance pick has generated under $-40 \mathrm{~dB}$ at $10.00 \mathrm{GHz}$. Therefore, in the proposed design, the antenna's operating band is from $2.26 \mathrm{GHz}$ to $11.00 \mathrm{GHz}$, which covers the ultrawideband frequency. The simulated maximum gain of different modification structures of the antenna is depicted in Figure $4 \mathrm{~b}$. It is seen that the simulated maximum gain of different structures is $2.50 \mathrm{dBi}, 4.50 \mathrm{dBi}$, and $5.48 \mathrm{dBi}$, respectively. The overall assessment of the different structure designs is presented in Table 2. The significant effect has been observed on the antenna characteristics such as $S_{11}$ due to the variations of the length $l_{2}$ and height $h$ of the trapezoidal ground plane. Further, the effect of the reflection coefficient is depicted in Figure 5, when $l_{2}$ and $h$ are varied, while other parameters remain constant. It is examined that, when length $l_{2}$ is deceased $2 \mathrm{~mm}$ (i.e., $l_{2}=28 \mathrm{~mm}$ ) and other parameters remain constant, then the lower frequency has shifted to $2.23 \mathrm{GHz}$ from $2.26 \mathrm{GHz}$, and the upper frequency has shifted to $8.00 \mathrm{GHz}$ from $11.00 \mathrm{GHz}$, operating frequency band is decreased to $8.00 \mathrm{GHz}$ and generated one resonance frequency at $3.00 \mathrm{GHz}$ near to- $25 \mathrm{~dB}$. Furthermore, when length $l_{2}$ is increased $2 \mathrm{~mm}$ (i.e., $l_{2}=32 \mathrm{~mm}$ ) and other parameters remain constant, the lower frequency shifts to $2.24 \mathrm{GHz}$ from $2.26 \mathrm{GHz}$, and the upper frequency shifts to $7.00 \mathrm{GHz}$ from $11.00 \mathrm{GHz}$ with two resonances close to $-25 \mathrm{~dB}$. However, in these two scenarios, the antenna does not cover ultrawideband range. Therefore, it is noticeable that the proposed length $l_{2}=30 \mathrm{~mm}$ is optimized to get ultrawideband frequency. On the other hand, when ground plane height $h$ is decreased $1 \mathrm{~mm}$ (i.e., $h=16 \mathrm{~mm}$ ) and other parameters remain constant, then the antenna's operating frequency range is from $2.26 \mathrm{GHz}$ to $6.00 \mathrm{GHz}$ with single resonance at $4.00 \mathrm{GHz}$ under $-15 \mathrm{~dB}$, which does not cover ultrawideband. In this scenario, the upper frequency has shifted to $6.00 \mathrm{GHz}$ from $11.00 \mathrm{GHz}$. In addition, when height $h$ is increased $1 \mathrm{~mm}$ (i.e., $h=18 \mathrm{~mm}$ ) and other parameters remain constant, then the antenna generated multiple bands with lower reflection. In this case, the operating frequency range is from $2.26 \mathrm{GHz}$ to $3.00 \mathrm{GHz}$ with single resonance at $2.50 \mathrm{GHz}$ close to $-15 \mathrm{~dB}$, which does not cover ultrawideband. In this scenario, the upper frequency has shifted to $3.00 \mathrm{GHz}$ from $11.00 \mathrm{GHz}$. So, it is concluded that the proposed ground plane height $h=17 \mathrm{~mm}$ is the optimized value to achieve the operating frequency band from $2.26 \mathrm{GHz}$ to $11.00 \mathrm{GHz}$.

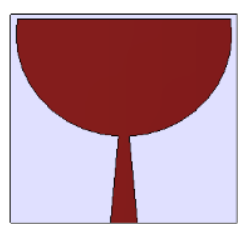

Front view

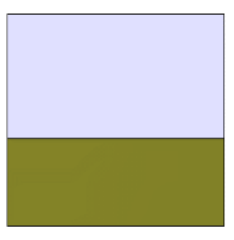

Rear view

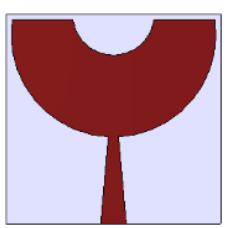

Front view

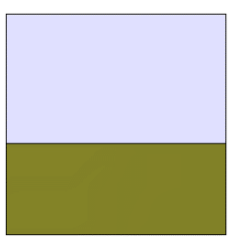

Rear view

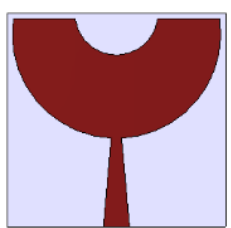

Front view

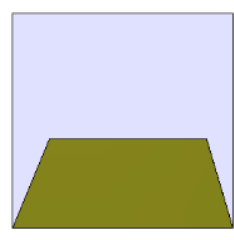

Rear view

(a)

(b)

(c)

Figure 3. Different modifications of the proposed prototype: (a) Normal patch design; (b) Slotted patch design; (c) Proposed design. 


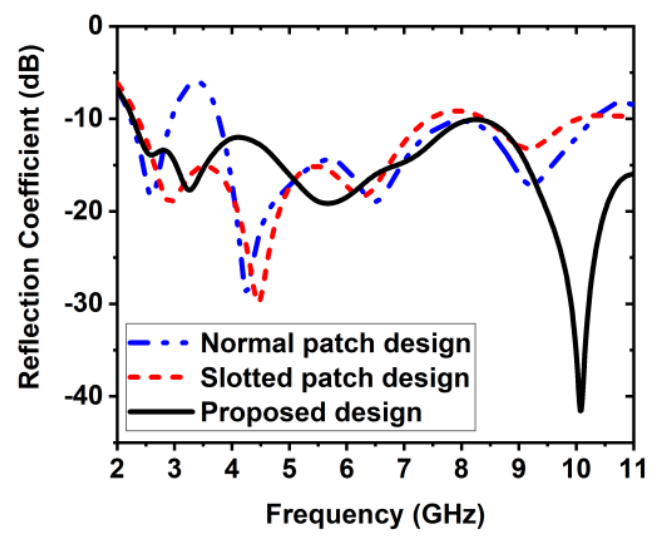

(a)

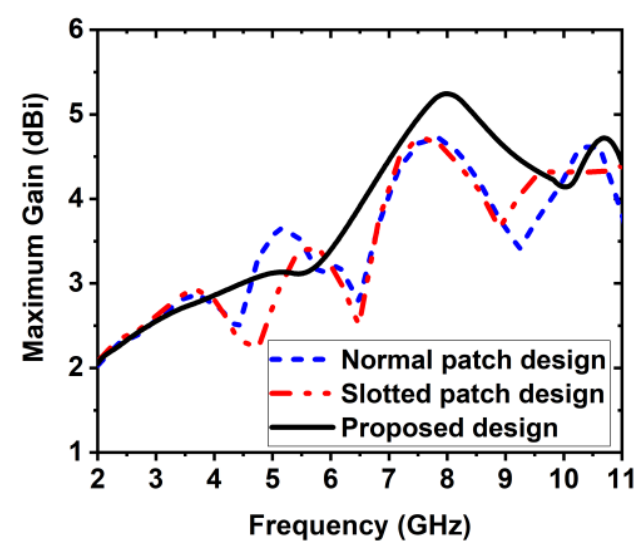

(b)

Figure 4. The effect of different design structure on: (a) $S_{11}$ (reflection coefficient); (b) Maximum gain.

Table 2. Different structure designs comparison table.

\begin{tabular}{cccc}
\hline Different Structure Designs & Operating Band (GHz) & Bandwidth (GHz) & Gain (dBi) \\
\hline Normal patch design & $2.26-3.00$ & 0.74 & 2.50 \\
Slotted patch design & $2.30-7.00$ & 4.70 & 4.50 \\
Proposed design & $2.26-11.00$ & 8.74 & 5.48 \\
\hline
\end{tabular}

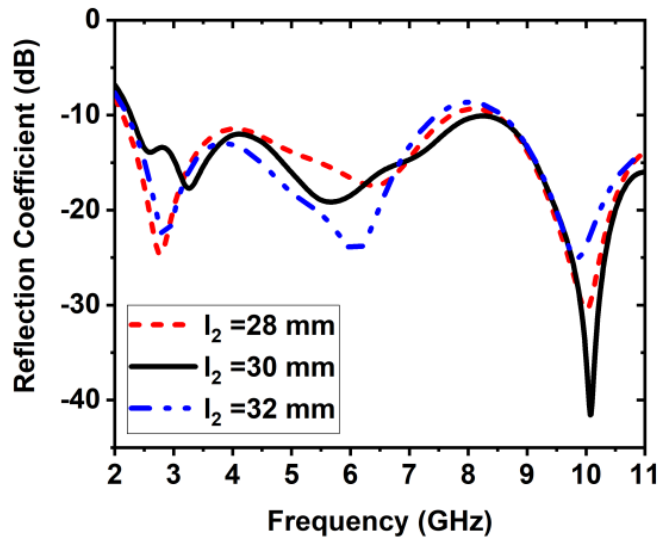

(a)

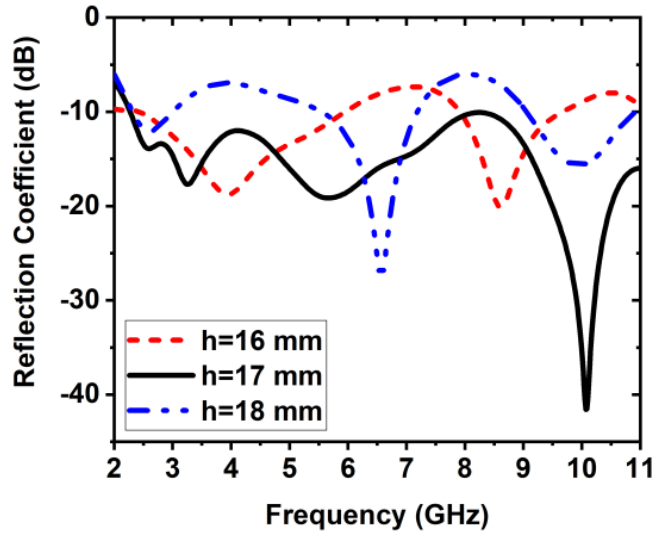

(b)

Figure 5. The effect of the reflection coefficient: (a) When length $\mathrm{l}_{2}=28 \mathrm{~mm}, 30 \mathrm{~mm}$, and $32 \mathrm{~mm}$; (b) When height $\mathrm{h}=16 \mathrm{~mm}, 17 \mathrm{~mm}$, and $18 \mathrm{~mm}$.

\section{Result and Discussion}

In this section, we discuss the obtained performance results of the antenna during measurement and simulation. The frequency-domain performance and time-domain performance are key factors in evaluating the antenna's performance. These performances have been examined and simulated through the CST and HFSS simulator and measured by using different types of equipment. However, the measured results of the fabricated prototype are compared with the simulation results to evaluate the performance. The Agilent N5227 PNA network analyzer is used to measure the $\mathrm{S}_{11}$ (reflection coefficient). It operates within $10 \mathrm{MHz}$ to $67 \mathrm{GHz}$. The UKM StarLab (Microwave Vision Group, Paris, French) near field antenna measurement system is used to measure the efficiency, gain and radiation pattern of the prototype. After that, primary data is collected in near-field and further converted to far-field by using the SatEnv software (Microwave Vision Group, Paris, France). The measurement setup of 
the PNA network analyzer (Agilent technologies, Inc., Santa Clara, CA, USA; N5227A 10 MHz-67 GHz) is demonstrated in Figure 6a, and the StarLab measurement setup is shown in Figure 6b.

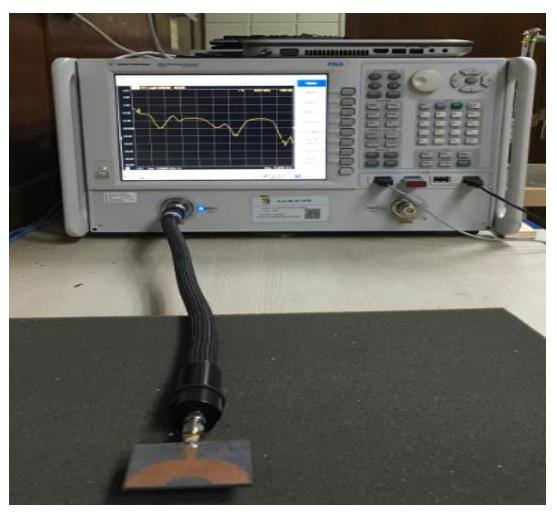

(a)

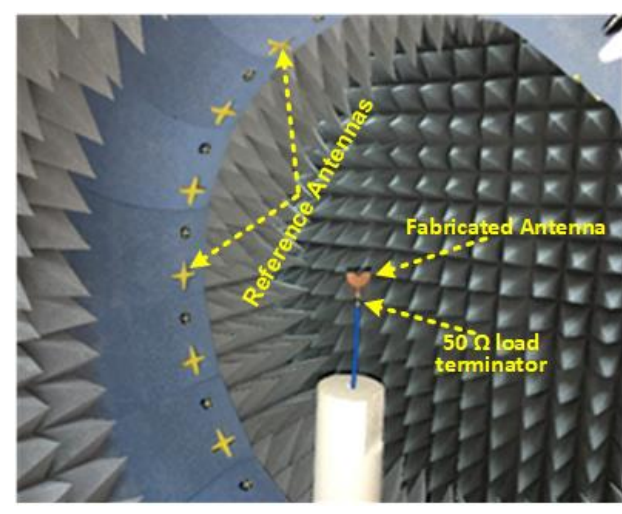

(b)

Figure 6. Measurement setup: (a) PNA measurement scenario; (b) StarLab measurement scenario.

\subsection{Performance Analysis in the Frequency Domain}

To evaluate the antenna performance in the frequency domain, the simulated surface current distribution, simulated and measured reflection coefficient, gain and radiation pattern characteristics are illustrated in this section. The circulation of the surface current of the prototype for three different resonances of $3.50 \mathrm{GHz}, 5.50 \mathrm{GHz}$, and $10.00 \mathrm{GHz}$ is displayed in Figure 7. It is determined that the highest predominant surface current zone of the prototype is the lowermost edge of the semicircle radiating patch, around the feeding line, as well as the top and side edges of the trapezoidal ground plane. It is also seen that at $5.50 \mathrm{GHz}$ and $10.00 \mathrm{GHz}$ frequencies, the moderate current conduction area is in the top semicircle-shaped slot of the patch. Moreover, there exists a slight number of nulls on the radiating patch at higher frequency (i.e., at $10.00 \mathrm{GHz}$ ) due to the higher-order current mode. Figure 8a represents the measured and simulated $S_{11}$ (reflection coefficient) of the proposed prototype. The simulated results were obtained from both CST and HFSS. The proposed structure attained a $-10 \mathrm{~dB}$ reflection coefficient of $8.74 \mathrm{GHz}(2.26-11.00 \mathrm{GHz})$ impedance bandwidth. The lower-frequency bandwidth is sensitively affected due to use of the semicircle-shaped slot in the radiating patch and trapezoidal ground plane. However, the measured $S_{11}$ (reflection coefficient) has slightly shifted toward from $2.26 \mathrm{GHz}$ to $2.30 \mathrm{GHz}$ (i.e., $40 \mathrm{MHz}$ ) concerning the simulated result. So, the measured operating frequency range is from $2.30 \mathrm{GHz}$ to $11.00 \mathrm{GHz}$ (i.e., Bandwidth is $8.70 \mathrm{GHz}$ ). From the measurement outcomes, it is observed that resonance frequencies have produced at $3.60 \mathrm{GHz}, 4.90 \mathrm{GHz}$, and $8.50 \mathrm{GHz}$. The slight mismatch between the simulated and measured results may be due to fabrication and soldering tolerance. Otherwise, the simulated and measured outcomes exhibited good agreements through the entire bandwidth. Figure $8 \mathrm{~b}$ presents the measured and simulated gain curve. The measured maximum gain is achieved as $5.80 \mathrm{dBi}$ at $8.26 \mathrm{GHz}$. However, the measured and simulated 2D radiation patterns, together with co-polar and cross-polar of E-plane when phi $(\varphi)=0$, is shown in Figure 9 for three resonances of $3.50 \mathrm{GHz}, 5.50 \mathrm{GHz}$, and $10.00 \mathrm{GHz}$. It is determined that the simulation and measured outcomes show good agreement. Moreover, the proposed prototype illustrates stable directional radiation. It is also determined that at higher frequencies, antenna radiation shows the omnidirectional characteristics with some side lobes because at upper frequencies, many nulls may increase in current circulation that produces few side lobes. 


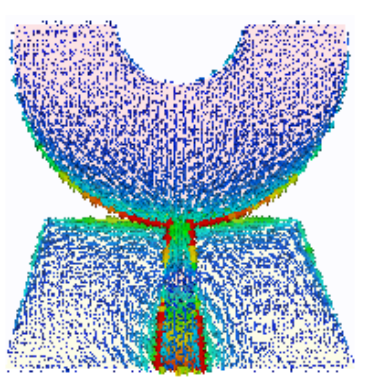

(a)

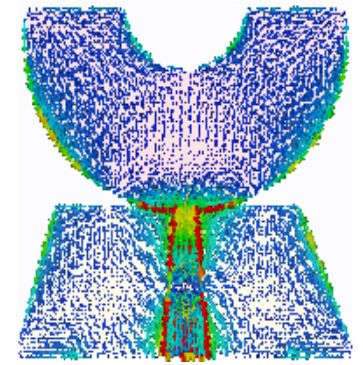

(b)

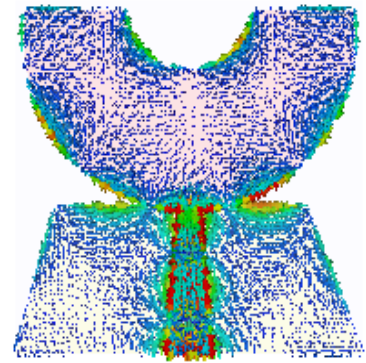

(c)

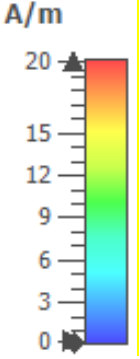

(d)

Figure 7. The surface current distribution at: (a) $3.50 \mathrm{GHz}$; (b) $5.50 \mathrm{GHz}$; (c) $10.00 \mathrm{GHz}$ and (d) scale

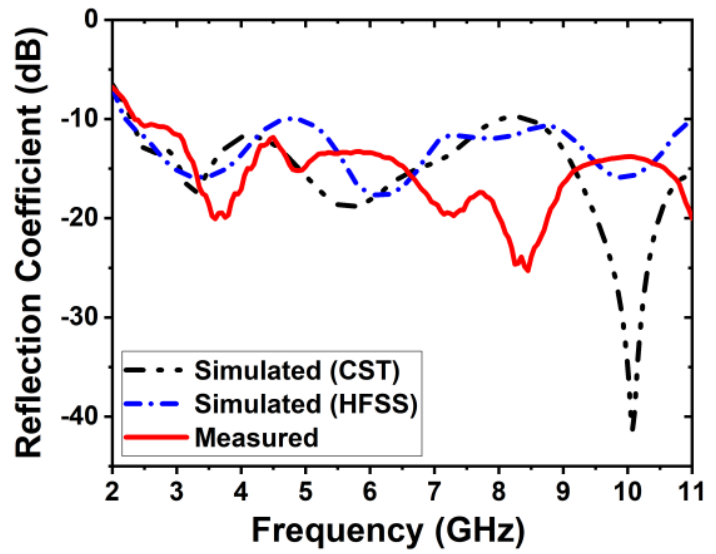

(a)

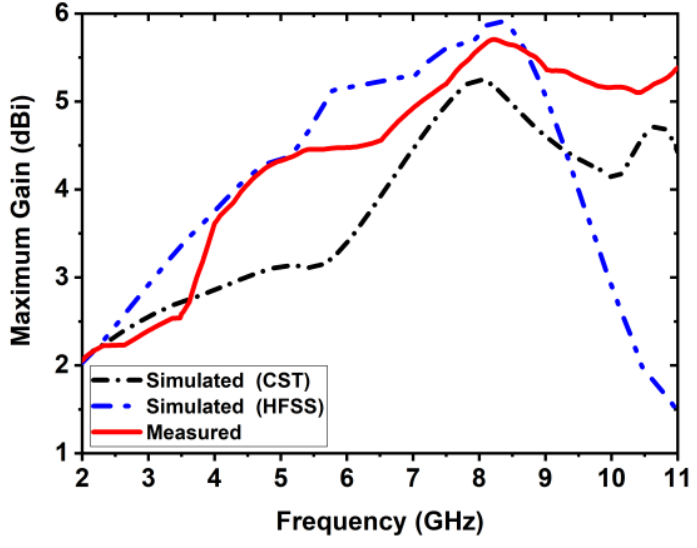

(b)

Figure 8. The measured and simulated: (a) Reflection coefficient $\left(\mathrm{S}_{11}\right)$ and (b) Maximum gain of the prototype.

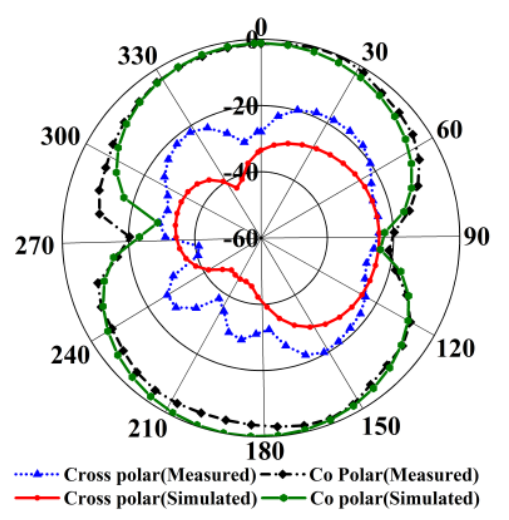

(a)

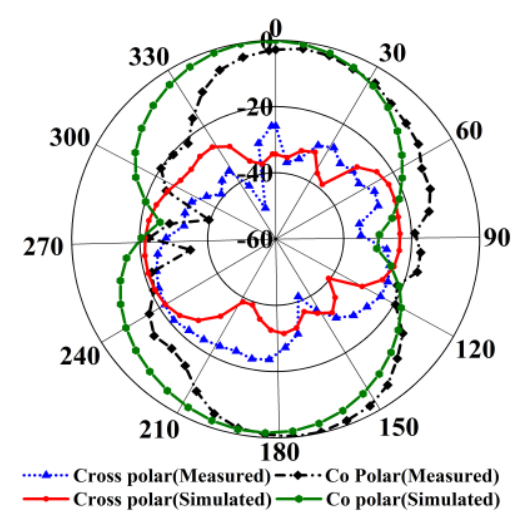

(b)

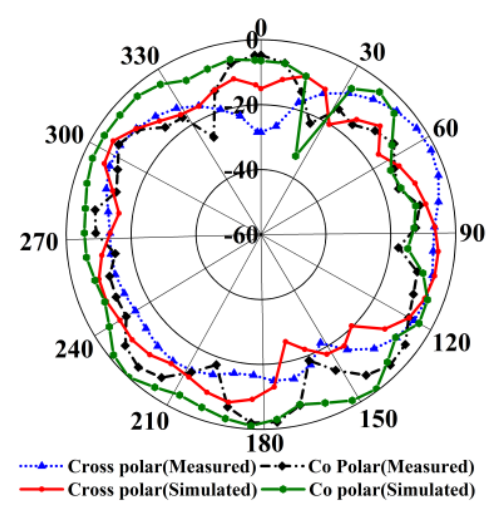

(c)

Figure 9. Simulated and measured 2D radiation pattern of E plane $(\varphi=0)$ of the proposed antenna at: (a) $3.50 \mathrm{GHz}$; (b) $5.50 \mathrm{GHz}$; (c) $10.00 \mathrm{GHz}$.

\subsection{Performance Analysis in the Time Domain}

It is noticeable that frequency-domain analysis alone may not ensure the antenna's performance. Therefore, for the assessment of the accurateness of the proposed antenna in the MWI system, it is essential to investigate the time-domain performance, including the input-output pulse waveform and fidelity factor. To investigate input-output pulse characteristics, two types of setups, such as 
face-to-face and side-by-side, are considered to evaluate the time-domain performance of the proposed prototype. In both cases, the distance of the two antennas is assumed to be $250 \mathrm{~mm}$. Overall, it is determined that, in both setups, the waveforms are nearly identical for transmitted and received signals, although it spread slightly.

Consequently, it is decided that, with a slight alteration, the prototype can emit a small pulse. The normalized magnitude scenario of the face-to-face and side-by-side setups is illustrated in Figure $10 \mathrm{a}, \mathrm{b}$. However, it is seen that, in a face-to-face scenario, the received pulses are nearly equal to the transmitted pulses in respect to the side-by-side setup, for the highly directive radiation. So, this setup is used in the breast imaging system. Another parameter of the antenna fidelity factor (FF) is expressed by the following formula [42]:

$$
F F=\max \frac{\int_{-\infty}^{+\infty} T(t) R(t-\tau) d t}{\sqrt{\int_{-\infty}^{+\infty}\left|T(t)^{2}\right| d t \int_{-\infty}^{+\infty}\left|R(t)^{2}\right| d t}}
$$

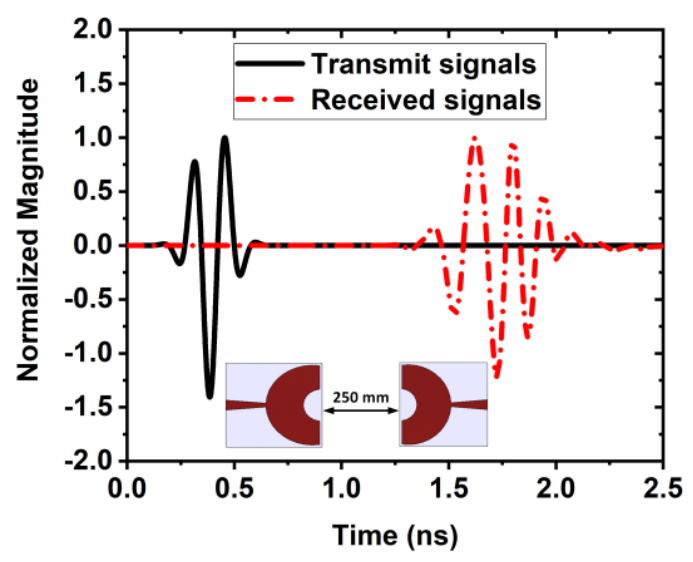

(a)

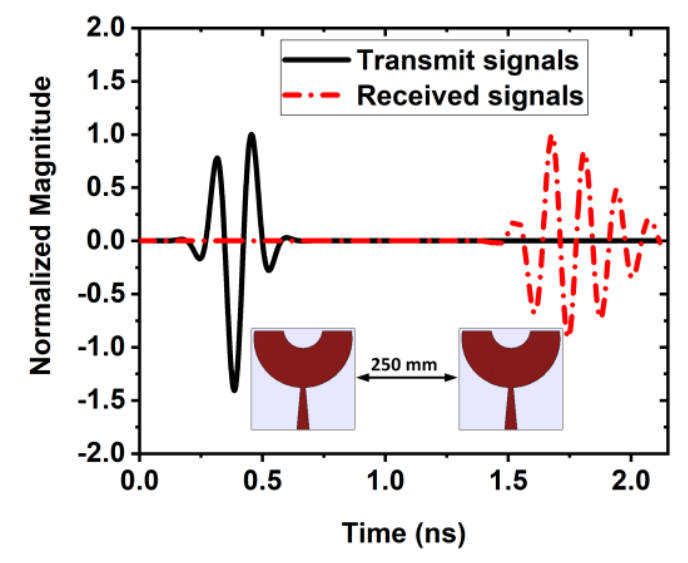

(b)

Figure 10. The normalized magnitude of the: (a) Face-to-face setup; (b) Side-by-side setup.

Here, $T(t)$ and $R(t)$ denote the transmitted and received pulses, respectively. The FF is calculated by the MATLAB programming language, and the values are $82 \%$ and $81 \%$ for face-to-face and side-by-side setups, correspondingly. These values indicate that the proposed system has minor alteration of the pulse while transmitting UWB impulse signals.

\section{Imaging Setup and Result Discussion}

In this section, the imaging setup and imaging results are investigated. The performance is investigated based on different parameters together with analyzing the backscattering signal, far-field directivity, near field directivity (NFD), and S-parameters. The proposed imaging setup is presented in Figure 11a,c. To investigate the 16-antenna array performance, a breast phantom is used for identifying breast tumors. A 16-antenna array consists of 16 proposed antennas, which are placed horizontally and vertically around the breast phantom. In the 16-antenna array imaging scenario, an eight-antenna array is positioned horizontally, and the other eight-antenna array is positioned vertically, neighboring the breast phantom with the same distance from each other. In this scanning procedure, a single antenna acts as a transmitter, which is transmitting microwave pulses, and the remaining 15 antennas act as receivers, which are receiving the backscattered signal. The procedure is repetitive for every 16 antennas acting as a transmitter. 
The heterogeneous phantom has three layers: the skin layer, the fat layer, and the tumor. The phantom properties are selected based on the normal human breast tissue obtained from reduction surgeries [43]. Reference values are obtained from the literature [43,44]. However, the considered relative permittivity, conductivity, and width of the skin layer are $39,1.5 \mathrm{~S} / \mathrm{m}$, and $2.50 \mathrm{~mm}$, respectively. The radius of the breast phantom is $45 \mathrm{~mm}$. The fat layer has the relative permittivity and conductivity of 15 and $0.14 \mathrm{~S} / \mathrm{m}$, respectively. In this breast scanning, the tumor tissue radius is $2.50 \mathrm{~mm}$ with a relative permittivity of 57 and $5 \mathrm{~S} / \mathrm{m}$ of conductivity, and it has been placed at $25 \mathrm{~mm}$ depth inside the phantom. The dielectric properties of the breast tissues with tumor are presented in Table 3. The stated properties of different tissue layers are in a single frequency of $3.00 \mathrm{GHz}$. The skin, fat, and tumor relative permittivity versus frequency is presented in Figure 11d. The total of $16 \times 15=240$ scanned location has been assessed for a whole scanning. The microwave signals are propagated through the breast phantom. Figure 12a demonstrated the far-field directivity of the antenna. It is observed that the radiation is propagating, covering the whole phantom.

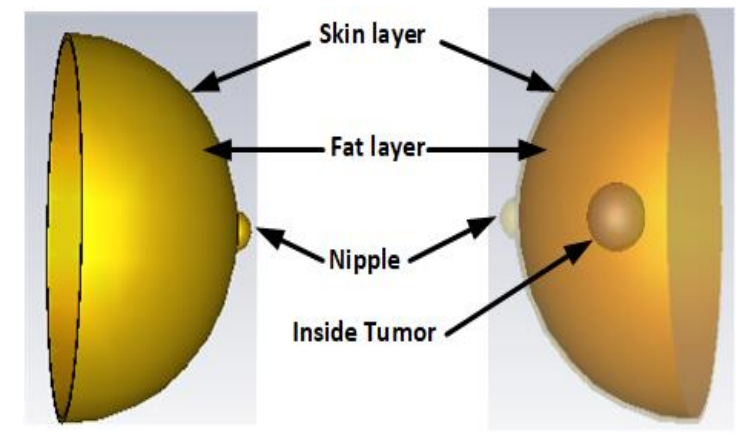

(a)

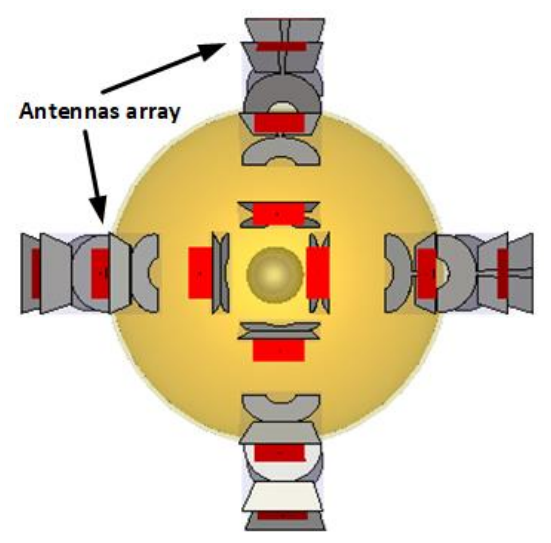

(c)

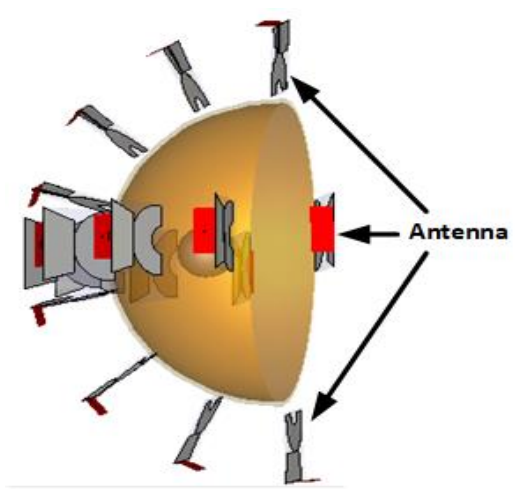

(b)

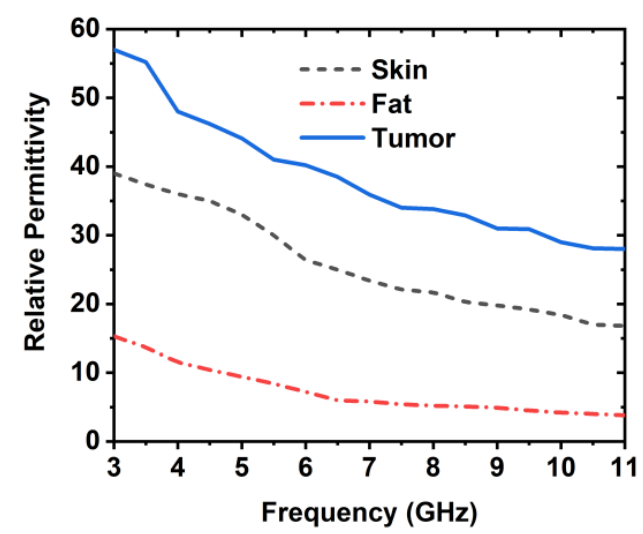

(d)

Figure 11. Proposed breast imaging setup: (a) Breast phantom tissues layer with and without tumor; (b) Right side view of 16-antenna array imaging setup; (c) Top view of 16-antenna array imaging setup; (d) The relative permittivity of different tissue layers of the phantom.

Table 3. The dielectric properties of the human breast tissues with tumor at $3.00 \mathrm{GHz}$ frequency.

\begin{tabular}{ccc}
\hline Name of the Tissues & Relative Permittivity $\left(\varepsilon_{\boldsymbol{r}}\right)$ & Conductivity $(\sigma)$ \\
\hline Skin & 39 & 1.5 \\
Fat & 15 & 0.14 \\
Tumor & 57 & 5 \\
\hline
\end{tabular}




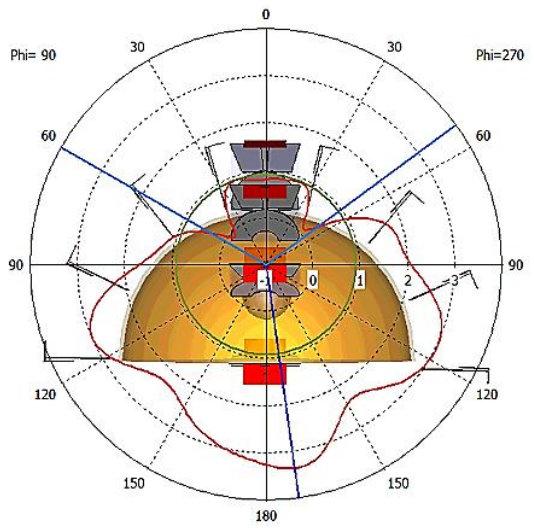

(a)

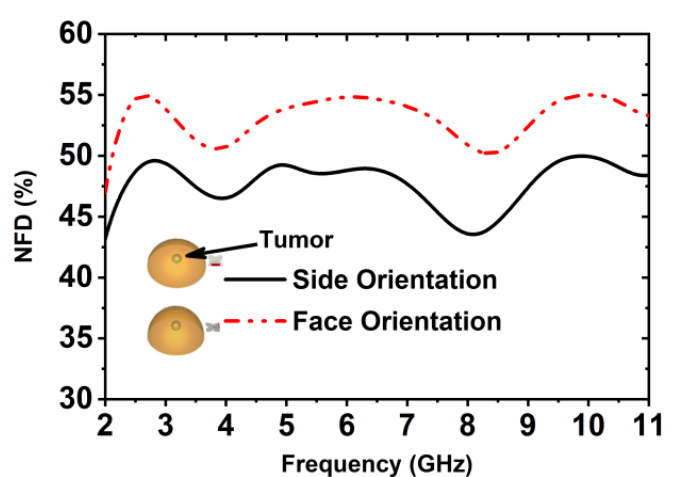

(b)

Figure 12. (a) Far-field directivity; (b) Near field directivity of the imaging setup.

The NFD is the ratio of emitted power by the transmitting antenna, and the emitted power received over the surface, which can be expressed by the following formula [45]:

$$
N F D=\frac{P_{f}}{P_{T}}
$$

where $P_{f}$ denotes the power emitted inside the phantom, and $P_{T}$ denotes the emitted power over the surface of the phantom. Figure $12 \mathrm{~b}$ demonstrates the NFD of the antenna with the proposed imaging setup with a tumor. It is found that NFD intended for the offered imaging setup is approximately $56 \%$ when antenna setup is as face orientation. Besides, it also observed that NFD is about $49 \%$ when antenna setup is as side orientation. This means that for the proposed imaging setup, about $56 \%$ power is emitted through the breast tissue. Figure 13 represents the S-parameters $\left(S_{1,1}\right.$ to $\left.S_{16,1}\right)$ response of the healthy breast (i.e., without tumor) and unhealthy breast (i.e., with a tumor) when antenna one is excited and the remaining 15 antennas are receiving the scattered signals. S-parameters means scattering parameters of the antenna. The digit associated with $\mathrm{S}$ represents the antenna number (i.e., 1 means antenna no. 1, 2 means antenna no. 2, 3 means antenna no. 3, .. 16 means antenna no. 16 , and so on). However, $S_{2,1}$ represents backscattering signals from antenna 1 ; received by antenna 2, $\mathrm{S}_{3,1}$ represents backscattering signals from antenna 1 ; received by antenna $3, \mathrm{~S}_{12,1}$ represents backscattering signals from antenna 1 ; received by antenna 12 , and so on.

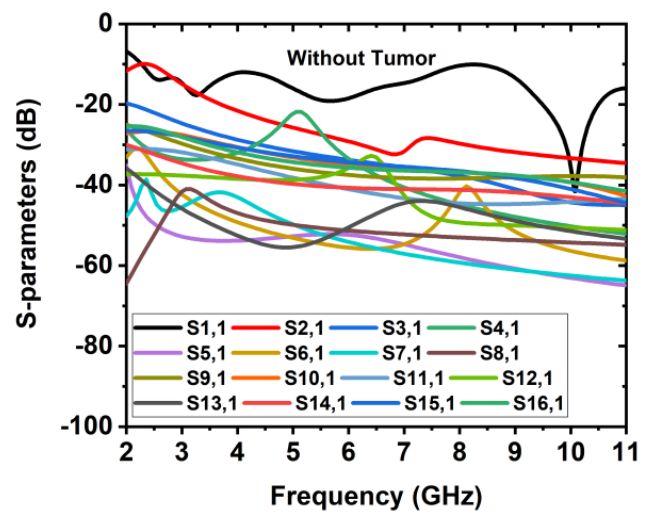

(a)

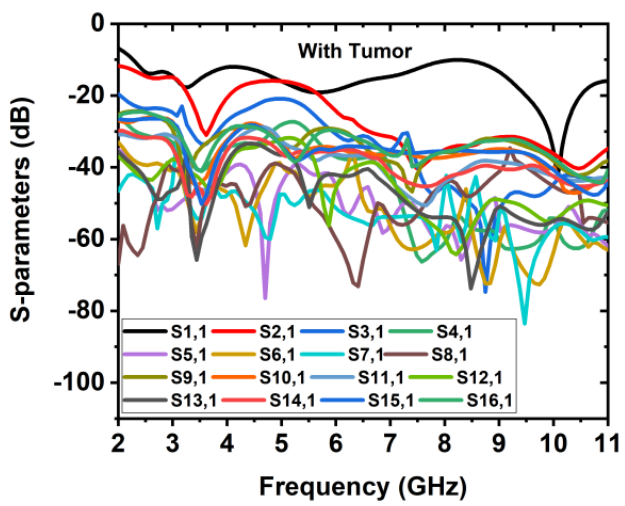

(b)

Figure 13. S-parameters of the arrays setup: (a) Without the presence of tumor; (b) With the presence of tumor inside breast phantom. 
The reflection response of the transmitter antenna is comparatively unchanged in the imaging setup. There is a significant distortion of the backscattering signal of the two graphs in Figure 13a,b. Due to the absence of the tumor, the highest peak resonance frequency is recorded about $-62 \mathrm{~dB}$. In contrast, in the presence of the tumor, the peak resonance is approximately $-82 \mathrm{~dB}$ in the operating frequency band. The scattered signals are different due to the higher dielectric properties of the tumor compared to the normal breast tissues. Thus, this indicates that the antenna array system setup with the proposed antenna can be a suitable candidate for breast imaging to identify the tumor by investigating backscattering signals proficiently. Then, the backscattered signal data are collected from the imaging setup and analyzed, processed by using the IC-DAS image reconstruction algorithm [1] using the MATLAB platform. After processing the data by the algorithm, the target imaging result is illustrated in Figure 14. The reconstructed images of the breast phantom without tumor are presented in Figure 14a and the phantom with the tumor is presented in Figure 14b. It is examined that the target tumor has been visibly detected with a red color. However, it is noticeable that our proposed system can be a decent candidate for microwave breast imaging to identify the tumor by examining the backscattering signals proficiently. A comparative study of the stated antennas with the proposed antenna is listed in Table 4. However, the comparison parameters are antenna type, dimension, operating frequency range, fractional bandwidth (FBW), gain, scanning position, application, etc. Lastly, the proposed antenna is better than other reported antennas in terms of wider bandwidth, higher FBW, and stable gain with respect to dimension. The proposed system has a 16-antenna elements array, which covers $16 \times 15$ scanned points that help to get substantial imaging data points and produces high-resolution imaging compared to other systems reported in the literature.

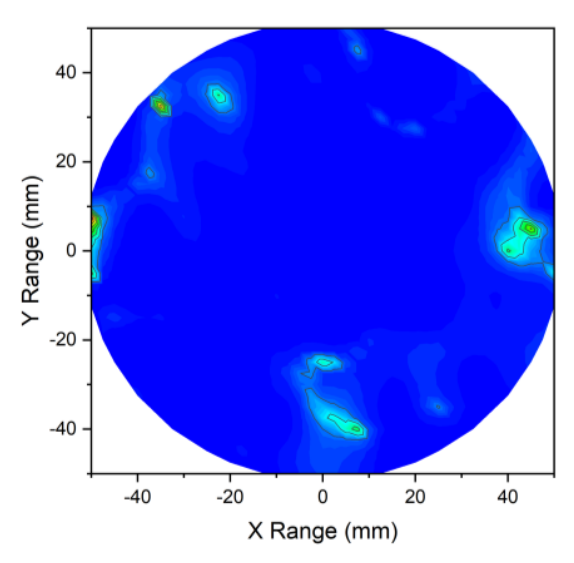

(a)
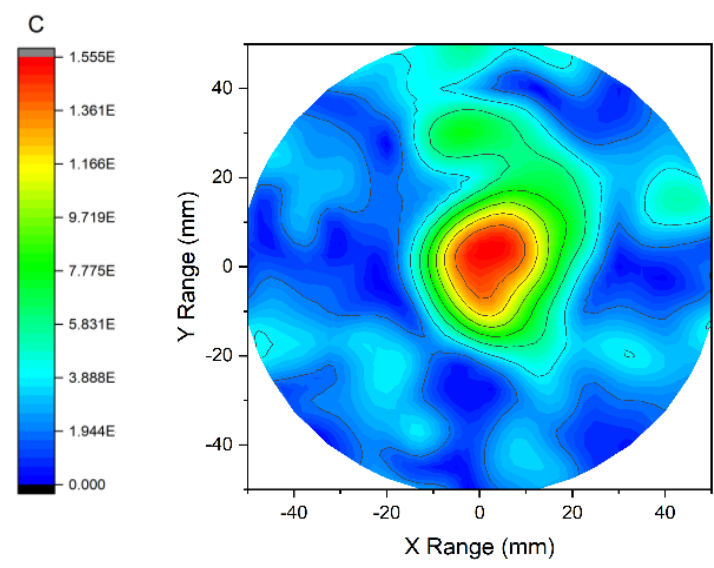

(b)

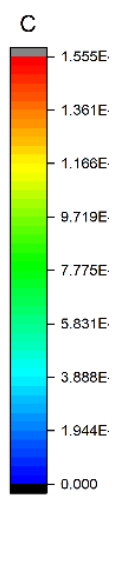

Figure 14. Reconstructed Images of the breast phantom: (a) Phantom without tumor; (b) Phantom with tumor. 
Table 4. Performance comparison outcomes among the reported antennas and the proposed antenna.

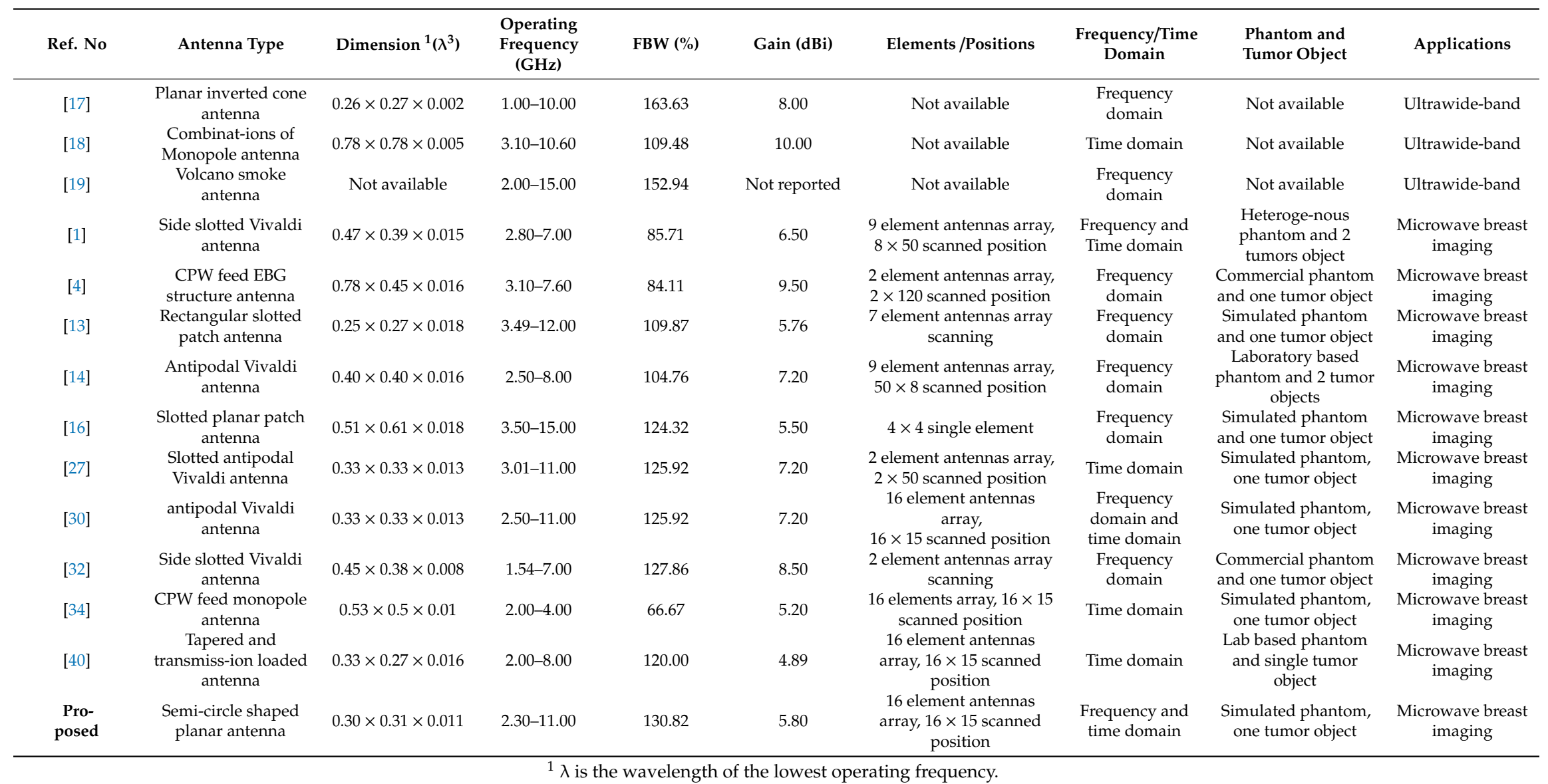

${ }^{1} \lambda$ is the wavelength of the lowest operating frequency. 


\section{Conclusions}

In this article, a compact planar UWB antenna is designed, fabricated, and inspected for breast tumor imaging to detect tumors in the breast. The antenna is compact in dimension: $0.30 \lambda \times 0.31 \lambda \times 0.011 \lambda$, where $\lambda$ is the wavelength of the lowest operating frequency, and it has attained an operating bandwidth of $8.70 \mathrm{GHz}(2.30-11.00 \mathrm{GHz}, 130.82 \%$ fractional bandwidth) with a maximum of $5.80 \mathrm{dBi}$ gain, as well as stable radiation characteristics. The simulated and experimental outcomes are evaluated to validate the performance of a single antenna with UWB features. The antenna demonstrates outstanding performance in frequency-domain and time-domain performance for the face-to-face setup with a higher fidelity factor and shows good near-field directivity (NFD). A breast imaging platform with 16 antennas is designed. A breast phantom with a tumor is investigated, analyzed, and processed by using the IC-DAS algorithm for evaluating the imaging performance, and tumor is detected. Finally, it is observed that the proposed antenna is a good candidate for initial breast tumor identification through microwave imaging.

Author Contributions: A.H. and M.T.I. (Md. Tarikul Islam) made momentous contributions to conception, design, result examination, preparation, manuscript writing. M.T.I. (Md. Tarikul Islam) and M.S. revised of the manuscript. A.H., M.T.I. (Md. Tarikul Islam), M.S. and M.T.I. (Mohammad Tariqul Islam) have done the investigational outcomes extraction and inspection as well as M.T.I. (Mohammad Tariqul Islam) supervised and funded the entire research. M.E.H.C. reviewed the manuscript, design optimization, characterization, and provided intellectual suggestions. M.E.H.C. and H.R. have revised the manuscript judgmentally for significant intellectual content and provided precious advice. All authors have read and agreed to the published version of the manuscript.

Funding: This work was made possible by NPRP12S-0227-190164 from the Qatar National Research Fund, a member of Qatar Foundation, Doha, Qatar. The statements made herein are solely the responsibility of the authors. The project was also funded by the Deanship of Scientific Research (DSR), King Abdulaziz University, Jeddah, Saudi Arabia under grant no. KEP-MSc-3-135-39. It was supported also by the Ministry of Education Malaysia research grant no. FRGS/1/2018/TK04/UKM/01/3.

Acknowledgments: The publication of this article was funded by the Qatar National Library. This work was made possible by NPRP12S-0227-190164 from the Qatar National Research Fund, a member of Qatar Foundation, Doha, Qatar. The statements made herein are solely the responsibility of the authors. The project was also funded by the Deanship of Scientific Research (DSR), King Abdulaziz University, Jeddah, Saudi Arabia under grant no. KEP-MSc-3-135-39. The authors, therefore, acknowledge with thanks DSR technical and financial support. It was supported also by the Ministry of Education Malaysia research grant no. FRGS/1/2018/TK04/UKM/01/3.

Conflicts of Interest: The authors declare no conflict of interest.

\section{References}

1. Islam, M.; Mahmud, M.; Islam, M.T.; Kibria, S.; Samsuzzaman, M. A low cost and portable microwave imaging system for breast tumor detection using UWB directional antenna array. Sci. Rep. 2019, 9, 1-13. [CrossRef] [PubMed]

2. Islami, F.; Torre, L.A.; Drope, J.M.; Ward, E.; Jemal, A. Global cancer in women: Cancer control priorities. Cancer Epidemiol. Biomarkers Prev. 2017, 26, 458-470. [CrossRef] [PubMed]

3. Zhang, H. Microwave Imaging for Ultra-Wideband Antenna Based Cancer Detection. Ph.D. Thesis, The University of Edinburgh, Edinburgh, UK, July 2015.

4. Mahmud, M.Z.; Islam, M.T.; Misran, N.; Kibria, S.; Samsuzzaman, M. Microwave imaging for breast tumor detection using uniplanar AMC based CPW-fed microstrip antenna. IEEE Access 2018, 6, 44763-44775. [CrossRef]

5. O'Loughlin, D.; O’Halloran, M.; Moloney, B.M.; Glavin, M.; Jones, E.; Elahi, M.A. Microwave breast imaging: Clinical advances and remaining challenges. IEEE Trans. Biomed. Eng. 2018, 65, 2580-2590. [CrossRef] [PubMed]

6. Mettler Jr, F.A.; Wiest, P.W.; Locken, J.A.; Kelsey, C.A. CT scanning: Patterns of use and dose. J. Radiol. Prot. 2000, 20, 353. [CrossRef]

7. Nikolova, N.K. Microwave imaging for breast cancer. IEEE Microw. Mag. 2011, 12, 78-94. [CrossRef]

8. Jacobs, M.A.; Ibrahim, T.S.; Ouwerkerk, R. MR imaging: Brief overview and emerging applications. Radiographics 2007, 27, 1213-1229. [CrossRef] 
9. Baltzer, P.A.; Benndorf, M.; Dietzel, M.; Gajda, M.; Runnebaum, I.B.; Kaiser, W.A. False-positive findings at contrast-enhanced breast MRI: A BI-RADS descriptor study. AJR Am. J. Roentgenol. 2010, 194, 1658-1663. [CrossRef]

10. Narouze, S.N. Atlas of Ultrasound-Guided Procedures in Interventional Pain Management; Springer: New York, NY, USA, 2018.

11. Lim, H.B.; Nhung, N.T.T.; Li, E.-P.; Thang, N.D. Confocal microwave imaging for breast cancer detection: Delay-multiply-and-sum image reconstruction algorithm. IEEE Trans. Biomed. Eng. 2008, 55, 1697-1704. [PubMed]

12. Conceição, R.C.; Mohr, J.J.; O’Halloran, M. An Introduction to Microwave Imaging for Breast Cancer Detection; Springer: New York, NY, USA, 2016.

13. Islam, M.T.; Samsuzzaman, M.; Faruque, M.; Singh, M.J.; Islam, M. Microwave imaging based breast tumor detection using compact wide slotted UWB patch antenna. Optoelectron. Adv. Mater. Rapid Commun. 2019, 13, 448-457.

14. Kibria, S.; Samsuzzaman, M.; Islam, M.T.; Mahmud, M.Z.; Misran, N.; Islam, M.T. Breast phantom imaging using iteratively corrected coherence factor delay and sum. IEEE Access 2019, 7, 40822-40832. [CrossRef]

15. Halili, K.; Ojaroudi, M.; Ojaroudi, N. Ultrawideband monopole antenna for use in a circular cylindrical microwave imaging system. Microw. Opt. Technol. Lett. 2012, 54, 2202-2205. [CrossRef]

16. Sugitani, T.; Kubota, S.; Toya, A.; Xiao, X.; Kikkawa, T. A compact $4 \times 4$ planar UWB antenna array for 3-D breast cancer detection. IEEE Antennas Wirel. Propag. Lett. 2013, 12, 733-736. [CrossRef]

17. Suh, S.-Y.; Stutzman, W.L.; Davis, W.A. A new ultrawideband printed monopole antenna: The planar inverted cone antenna (PICA). IEEE Trans. Antennas Propag. 2004, 52, 1361-1364. [CrossRef]

18. Powell, J.; Chandrakasan, A. Spiral slot patch antenna and circular disc monopole antenna for 3.1-10.6 GHz ultra wideband communication. ISAP 2004 2004, 8, 1-10.

19. Paulsen, L.; West, J.; Perger, W.; Kraus, J. Recent investigations on the volcano smoke antenna. In Proceedings of the IEEE Antennas and Propagation Society International Symposium. Digest. Held in conjunction with: USNC/CNC/URSI North American Radio Sci. Meeting (Cat. No. 03CH37450), Columbus, OH, USA, 22-27 June 2003; pp. 845-848.

20. Hossain, A.; Islam, M.T.; Almutairi, A.F.; Singh, M.S.J.; Mat, K.; Samsuzzaman, M. An octagonal ring-shaped parasitic resonator based compact ultrawideband antenna for microwave imaging applications. Sensors 2020, 20, 1354. [CrossRef]

21. Mahmud, M.Z.; Islam, M.T.; Almutairi, A.F.; Samsuzzaman, M.; Acharjee, U.; Islam, M.T. A parasitic resonator-based diamond-shaped microstrip antenna for microwave imaging applications. Electronics 2019, 8, 434. [CrossRef]

22. Mewara, H.S.; Deegwal, J.K.; Sharma, M.M. A slot resonators based quintuple band-notched Y-shaped planar monopole ultra-wideband antenna. Aeu-Int. J. Electron C. 2018, 83, 470-478. [CrossRef]

23. Ojaroudi, M.; Civi, O.A. Bandwidth enhancement of small square monopole antenna using self-complementary structure for microwave imaging system applications. Appl. Comput. Electromagn. Soc. J. 2015, 30, 1360-1365.

24. Li, T.; Zhai, H.; Li, L.; Liang, C.; Han, Y. Compact UWB antenna with tunable band-notched characteristic based on microstrip open-loop resonator. IEEE Antennas Wirel. Propag. Lett. 2012, 11, 1584-1587. [CrossRef]

25. Borja, B.; Tirado, J.A.; Jardon, H. An overview of UWB antennas for microwave imaging systems for cancer detection purposes. Prog. Electromagn. Res. B 2018, 80, 173-198. [CrossRef]

26. Hasim, N.S.B.; Ping, K.A.H.; Islam, M.T.; Mahmud, M.Z.; Sahrani, S.; Mat, D.A.A.; Zaidel, D.N.A. A slotted UWB antipodal vivaldi antenna for microwave imaging applications. Prog. Electromagn. Res. 2019, 80, 35-43. [CrossRef]

27. Islam, M.T.; Samsuzzaman, M.; Islam, M.; Kibria, S.; Singh, M.J. A homogeneous breast phantom measurement system with an improved modified microwave imaging antenna sensor. Sensors 2018, 18, 2962. [CrossRef] [PubMed]

28. Natarajan, R.; George, J.V.; Kanagasabai, M.; Shrivastav, A.K. A compact antipodal Vivaldi antenna for UWB applications. IEEE Antennas Wirel. Propag. Lett. 2015, 14, 1557-1560. [CrossRef]

29. Salleh, A.; Yang, C.C.; Alam, T.; Singh, M.S.J.; Samsuzzaman, M.; Islam, M.T. Development of microwave brain stroke imaging system using multiple antipodal vivaldi antennas based on raspberry Pi technology. J. Kejuruterran 2020, 32, 1-6. 
30. Samsuzzaman, M.; Islam, M.T.; Islam, M.T.; Shovon, A.A.; Faruque, R.I.; Misran, N. A 16-modified antipodal Vivaldi antenna array for microwave-based breast tumor imaging applications. Microw. Opt. Technol. Lett. 2019, 61, 2110-2118. [CrossRef]

31. Selvaraj, V.; Srinivasan, P.; Kumar, J.; Krishnan, R.; Annamalai, K. Highly directional microstrip ultra wide band antenna for microwave imaging system. Acta Graphica: Znanstveni Časopis za Tiskarstvo $i$ Grafičke Komunikacije 2017, 28, 35-40.

32. Islam, M.T.; Mahmud, M.Z.; Misran, N.; Takada, J.-I.; Cho, M. Microwave breast phantom measurement system with compact side slotted directional antenna. IEEE Access 2017, 5, 5321-5330. [CrossRef]

33. Mahmud, M.; Islam, M.T.; Misran, N.; Almutairi, A.F.; Cho, M. Ultra-wideband (UWB) antenna sensor based microwave breast imaging: A review. Sensors 2018, 18, 2951. [CrossRef]

34. Porter, E.; Bahrami, H.; Santorelli, A.; Gosselin, B.; Rusch, L.A.; Popović, M. A wearable microwave antenna array for time-domain breast tumor screening. IEEE Trans. Med. Imaging 2016, 35, 1501-1509. [CrossRef]

35. Saeidi, T.; Ismail, I.; Wen, W.P.; Alhawari, A.R. Ultra-wideband elliptical patch antenna for microwave imaging of wood. Int. J. Microw. Wirel. Trans. 2019, 11,948-966. [CrossRef]

36. Islam, M.; Islam, M.T.; Faruque, M.R.I.; Samsuzzaman, M.; Misran, N.; Arshad, H. Microwave imaging sensor using compact metamaterial UWB antenna with a high correlation factor. Materials 2015, 8, 4631-4651. [CrossRef] [PubMed]

37. Azim, R.; Islam, M.T.; Misran, N. Compact tapered-shape slot antenna for UWB applications. IEEE Antennas Wirel. Propag. Lett. 2011, 10, 1190-1193. [CrossRef]

38. Islam, M.T.; Samsuzzaman, M.; Islam, M.T.; Kibria, S. Experimental breast phantom imaging with metamaterial-inspired nine-antenna sensor array. Sensors 2018, 18, 4427. [CrossRef] [PubMed]

39. Jafari, H.; Deen, J.; Hranilovic, S.; Nikolova, N. Co-polarised and cross-polarised antenna arrays for breast, cancer detection. IET Microw. Antennas Propag. 2007, 1, 1055-1058. [CrossRef]

40. Porter, E.; Kirshin, E.; Santorelli, A.; Coates, M.; Popović, M. Time-domain multistatic radar system for microwave breast screening. IEEE Antennas Wirel. Propag. Lett. 2013, 12, 229-232. [CrossRef]

41. Islam, M.T.; Samsuzzaman, M.; Rahman, M.; Islam, M.T. A compact slotted patch antenna for breast tumor detection. Microw. Opt. Technol. Lett. 2018, 60, 1600-1608. [CrossRef]

42. Quintero, G.; Zurcher, J.-F.; Skrivervik, A.K. System fidelity factor: A new method for comparing UWB antennas. IEEE Antennas Wirel. Propag. Lett. 2011, 59, 2502-2512.

43. Lazebnik, M.; Popovic, D.; McCartney, L.; Watkins, C.B.; Lindstrom, M.J.; Harter, J.; Sewall, S.; Ogilvie, T.; Magliocco, A.; Breslin, T.M. A large-scale study of the ultrawideband microwave dielectric properties of normal, benign and malignant breast tissues obtained from cancer surgeries. Phys. Med. Biol. 2007, 52, 6093-6115. [CrossRef]

44. Lazebnik, M.; McCartney, L.; Popovic, D.; Watkins, C.B.; Lindstrom, M.J.; Harter, J.; Sewall, S.; Magliocco, A.; Booske, J.H.; Okoniewski, M. A large-scale study of the ultrawideband microwave dielectric properties of normal breast tissue obtained from reduction surgeries. Phys. Med. Biol. 2007, 52, 2637-2656. [CrossRef]

45. K Amineh, R.; Trehan, A.; Nikolova, N.K. TEM horn antenna for ultra-wide band microwave breast imaging. Prog. Electromagn. Res. 2009, 13, 59-74. [CrossRef]

(C) 2020 by the authors. Licensee MDPI, Basel, Switzerland. This article is an open access article distributed under the terms and conditions of the Creative Commons Attribution (CC BY) license (http://creativecommons.org/licenses/by/4.0/). 